\title{
FILOSOFÍA Y PANDEMIA
}

Philosophy and pandemic

\author{
SAMUEL MADRID GUERRA BRAVO* \\ Investigador independiente, Quito-Ecuador \\ sguerrab@puce.edu.ec \\ Código ORCID: https://orcid.org/0000-0001-8019-4578
}

\begin{abstract}
Resumen
Este trabajo presenta tres aspectos críticos relacionados con la filosofía en estos tiempos de pandemia. El primero tiene que ver con el fin de la Lechuza de Minerva como símbolo universal de la filosofía, es decir el fin de la idea de que la filosofía solo llega a explicar el mundo una vez que han acaecido los hechos. Se defiende la idea de una simultaneidad de la filosofía con los hechos y un cierto poder transformador del pensamiento. El segundo realiza una distinción crítica, desde un horizonte latinoamericano y del Sur Global (que es desde donde los latinoamericanos debemos pensar si queremos filosofar con sentido), entre 'Metafísica/Ontología del ser universal y abstracto’ y 'Onto-logías históricas del ser-aquí. Se defiende la significatividad y el valor de las ontologías históricas como dispositivos teóricos de descolonización frente a las metafísicas. Las 'onto-logías históricas del ser-aquí se preguntan, no por el ser abstracto, sino por la existencia y la vida cotidiana puestas en peligro por la pandemia. Ello permite en la tercera parte posicionar a la vida, no solo como un valor ético capaz de orientar la acción humana, sino como fundamento universal y categoría crítica. Como conclusión se sostiene la idea de que la pandemia ha revelado el verdadero fin de la modernidad eurocéntrica y ha abierto el desafío de pensar en sociedades diversas pero iguales en el derecho a la existencia y a la vida.
\end{abstract}

Palabras clave

Filosofía, pandemia, metafísica, ontología, historicidad, descolonización.

Forma sugerida de citar: Guerra, Samuel (2021). Filosofía y pandemia. Sophia, colección de Filosofía de la Educación, 30, pp. 245-272.

* Investigador independiente. Fue docente de la Escuela de Filosofía de la Pontificia Universidad Católica del Ecuador (PUCE). Colaborador habitual de revistas de su área y editor de la Revista Logos de la Facultad de Ciencias Filosófico-Teológicas de la PUCE. 


\begin{abstract}
This work presents three critical aspects related to philosophy in these times of pandemic. The first has to do with the end of Minerva's Owl as a universal symbol of philosophy, that is, the end of the idea that philosophy only manages to explain the world once the events have occurred. The idea of a simultaneity of philosophy with the facts and a certain transforming power of thought is defended. The second makes a critical distinction, from a Latin American and Global South horizon (which is where Latin Americans must think if we want to philosophize with meaning), between 'Metaphysics / Ontology of the universal and abstract being' and 'Historical ontologies of the behere. The significance and value of historical ontologies as theoretical decolonization devices are defended against metaphysics. The 'historical onto-logies of being-here' ask themselves, not about being abstract, but about existence and daily life endangered by the pandemic. This allows in the third part to position life, not only as an ethical value capable of guiding human action, but also as a universal foundation and a critical category. As a conclusion, the idea that the pandemic has revealed the true end of Eurocentric modernity and has opened the challenge of thinking in diverse but equal societies in the right to existence and life is upheld.
\end{abstract}

\title{
Keywords
}

Philosophy, pandemic, metaphysics, ontology, historicity, decolonization.

\section{Introducción}

La filosofía es idéntica al espíritu de la época en la que esta aparece; la filosofía no está por encima de su tiempo, ella es solamente la conciencia de lo sustancial de su tiempo, o el saber pensante de lo que existe en el tiempo. De la misma manera, ningún individuo puede estar por encima de su tiempo;

el individuo es hijo de su época; lo esencial de la época es su propia esencia; el individuo se manifiesta solamente en una forma determinada. Nadie puede salir de lo sustancial de su época, como nadie puede salir de su propia piel. Por consiguiente, en una consideración esencial la filosofía no puede saltar su propio tiempo.

(Hegel, 1980).

El mundo ha vivido en estos meses un ajedrez de circunstancias mortales frente a las cuales la filosofía se ha visto abocada a probar su poder o su debilidad, su actualidad o caducidad. El drama radica en que ha debido hacerlo ante la amenaza inmisericorde de la muerte representada por un 'enemigo invisible': el coronavirus.

Hay algunos problemas que requieren un debate especial en Latinoamérica y el Sur Global. Por ejemplo: ¿Puede la filosofía decir su palabra simultáneamente a los hechos de la pandemia o debe callar y esperar a que esta sea superada o solucionada por las ciencias para reflexionar sobre lo ya acaecido? Esta cuestión es la primera que se debate en este artículo. 
La segunda cuestión es un esclarecimiento del real y verdadero poder de la filosofía; poder que según la tesis planteada debe basarse, tras el fin de la metafísica eurocéntrica, en una onto-logía histórica de nosotros mismos. Se explica cómo se entiende la diferencia entre 'metafísica/ontología' (que Europa utilizó como mecanismo de dominación) y onto-logía (alternativa de pensamiento que hace posible avanzar del 'no-ser' al que nos redujo el colonialismo al 'ser-aquí' o ser-histórico que somos).

La tercera cuestión realiza una valoración de la vida como fundamento universal y como manifestación privilegiada del 'ser-aquí' en tiempos de pandemia. La doble vulnerabilidad de la vida en la región, ante la colonialidad y ante el coronavirus, brinda la ocasión para una reflexión onto-lógica.

Se concluye con una hipótesis: la pandemia se ha constituido en el verdadero fin de la modernidad eurocéntrica. Y, ojalá, en el verdadero fin de los imperialismos expansionistas y colonialistas. Se ha abierto una nueva etapa de la humanidad que algunos llaman transmodernidad y que, al parecer, no se dará en términos de transhumanismo (superación del hombre y de lo humano por la inteligencia artificial), sino en términos de un neo-humanismo abierto y solidario entre pueblos e individuos que ven, más allá del valor de la ciencia y la tecnología, que no se niega, la necesidad de cuidar-se y cuidar su casa común.

\section{El virus de la muerte (coronavirus) juega ajedrez con el Búho de Minerva (símbolo de la filosofía)}

El título de este primer apartado evoca a El séptimo sello, la famosa película de Ingmar Bergman en la que un caballero atormentado que vuelve a su castillo tras diez años de luchas inútiles en las Cruzadas, reta a la muerte a una partida de ajedrez en busca de respuestas a preguntas claves de la vida. La expresión 'Búho de Minerva' remite a Hegel, por un lado, y a los filósofos contemporáneos que han emitido sus reflexiones sobre la pandemia de coronavirus, por otro lado.

\section{Hegel, la manzana de la discordia}

Hegel escribió un memorable párrafo que se convirtió en un canon para la filosofía de los dos últimos siglos, en el Prefacio a los Principios de la filosofía del derecho, y que dice: 
Por lo demás, para decir aún una palabra sobre su pretensión de enseñar cómo debe ser el mundo, la filosofía llega siempre demasiado tarde. Como pensamiento del mundo sólo aparece en el tiempo después de que la realidad ha cumplido su proceso de formación y se ha terminado. Lo que enseña el concepto lo muestra necesariamente igual la historia, de modo que sólo en la madurez de la realidad aparece lo ideal frente a lo real y se hace cargo de este mundo mismo en su sustancia, erigido en la figura de un reino intelectual. Cuando la filosofía pinta su gris sobre gris, entonces ha envejecido una figura de la vida y, con gris sobre gris, no se deja rejuvenecer, sino solo conocer; el búho de Minerva sólo levanta su vuelo al romper el crepúsculo (Hegel, 1975, p. 26).

Este párrafo va a ser, por ahora, el motivo de la discordia. Últimamente se ha visto en las redes sociales como diversos filósofos han expresado sus ideas en escritos (artículos, ensayos, narrativas) que resultan coetáneos con el desarrollo de la pandemia. Y esta 'contemporaneidad' de la filosofía con la emergencia mundial de Covid-19 ha dado que pensar a unos y ha molestado a otros, sobre todo a aquellos que compaginan con la idea de que la filosofía emprende su vuelo, como la Lechuza de Minerva, al caer la tarde.

Sin embargo y ante la multiplicidad de reflexiones que los filósofos han emitido en estos mismos días, no se puede cerrar los ojos. Es posible entonces que esta profusión de narrativas nos esté diciendo algo que nos negamos a escuchar: que la metáfora de la Lechuza de Minerva puede ser no-adecuada para juzgar, ya no a la pandemia, sino a la filosofía misma. Y en auxilio de esta hipótesis se puede mencionar otro texto, memorable también, escrito por el mismo Hegel (1975) en el mismo Prefacio a los Principios de la filosofía del derecho:

La tarea de la filosofía es concebir lo que es, pues lo que es, es la razón. En lo que respecta al individuo, cada uno es, por otra parte, hijo de su tiempo; del mismo modo, la filosofía es su tiempo aprehendido en pensamientos. Es igualmente insensato creer que una filosofía puede ir más allá de su tiempo presente como que un individuo puede saltar por encima de su tiempo, más allá de Rodas. Pero si su teoría va en realidad más allá y se construye un mundo tal como debe ser, este existirá, por cierto, pero solo en su opinar, elemento dúctil en el que se puede plasmar cualquier cosa (p. 26).

Al contrastar estos párrafos, se puede ver que la metáfora del Búho de Minerva concibe a la filosofía como 'pensamiento del mundo', es decir como idea/razón/ conciencia/espíritu que ya no piensa el mundo 'externo' sino que se piensa a sí mismo: concepto puro que obviamente "aparece en el tiempo después que la realidad ha consumado su proceso de 
formación y se halla ya lista y terminada" (Hegel, 1975, p. 63). Incluso se puede reforzar este argumento si se menciona que, para Hegel, el 'largo tiempo' o 'larga duración' que se ha requerido para que la filosofía llegue a ser espíritu/razón que se piensa a sí mismo/a se refiere a que la filosofía, el espíritu de un pueblo y la cultura en un determinado tiempo, son el resultado del trabajo de todos los siglos pasados, desde las etapas y culturas primitivas hasta la etapa moderna que vivió Hegel (y la modernidad que vivimos, diríamos nosotros ahora) ${ }^{1}$.

En esta sucesión de etapas de los pueblos históricos (porque había otros pueblos 'sin historia', según Hegel), la filosofía aparecía como innovadora y pujante cuando los pueblos entraban en decadencia. ¿Por qué? Porque el espíritu, desilusionado del mundo terrestre que se había vuelto confuso, caótico y corrupto, se refugiaba en el mundo del pensamiento. Entonces, lo ideal aparecía sobre lo real y la filosofía no era otra cosa que el espíritu pensante que se piensa a sí mismo. En estos casos, la filosofía requirió de la maduración de la historia y el espíritu de aquellos pueblos, y era lógico equiparar la filosofía con el Búho de Minerva que levanta su vuelo al anochecer.

Surge entonces la pregunta de la discordia: ¿ es este idealismo absoluto el que preconizan los defensores de 'la filosofía como búho/lechuza/ mochuelo de Minerva'? Si lo hacen en el sentido de Hegel, está bien, es una opción. No obstante, se presume que lo que en realidad quieren defender es solamente la idea de que la filosofía, por ser re-flexión, requiere meditación lenta, sistemática, paciente, rigurosa, que debe aparecer cuando el vértigo de los hechos empíricos haya pasado y cuando las ciencias físicas y médicas hayan emitido su veredicto sobre la pandemia.

Pero Hegel (1975), sale al contraataque: según él, la filosofía tiene como tarea el 'concebir lo que es' y eso convierte al filósofo, en tanto individuo, en 'hijo de su tiempo'. Bajo esta consideración, la filosofía es 'su tiempo aprehendido en pensamientos', y es "insensato creer que una filosofía puede ir más allá de su tiempo presente como que un individuo puede saltar por encima de su tiempo, más allá de Rodas" (p. 63). Y, dice Hegel, esta filosofía que piensa el tiempo presente es 'simultánea' con la configuración del pueblo en el que se presenta y con todo lo que constituye la configuración de ese pueblo: gobierno, moralidad, vida social, aptitudes, costumbres, arte, ciencia, religión, relaciones bélicas y externas (y pandemias, añadiríamos). Pero sobre todo es 'simultánea' con "la decadencia de los Estados... y con el origen y crecimiento de algo más nuevo en que un principio más elevado encuentra su generación y desarrollo" (Hegel, 1980, pp. 261-262). 
Más claro no canta un gallo. Sin embargo, uno de los temas más discutidos en estos tiempos está centrado en saber si la filosofía puede decir algo simultáneamente a la evolución de la pandemia y su circunstancia o si debe esperar a que esta concluya su ciclo para entonces, y solo entonces, pensarla y hacer juicios sobre ella ${ }^{2}$.

\section{Covid-19 frente al Búho de Minerva}

El asunto comenzó con una temprana crítica a la publicación del libro La sopa de Wuhan ${ }^{3}$ (2020), que recoge artículos sobre la pandemia provenientes de las plumas de filósofos como Giorgio Agamben, Jean-Luc Nancy, Slavok Zizek, Byung-Chul Han, Judith Butler, Alan Badiou, María Galindo, Paul B. Preciado y otros ${ }^{4}$. La crítica, contenida en un Comunicado firmado por Colectivos pro-chinos radicados en España, se dirige sobre todo la portada y al título del libro que sugieren que el coronavirus tuvo su origen en Wuhan (China). El Colectivo entiende que tal portada y tal título, al señalar a China como el lugar de origen de la pandemia, demuestra odio, racismo y xenofobia, pues se le estaría culpando de haber originado la pandemia mundial: algo que no ha sido probado. "Si hay algo que al capitalismo colonial occidental le gusta hacer - dice el comunicado- es situar la problemática en una alteridad que lo aleje de cualquier responsabilidad" (Red de Diáspora China en España y Otros, 2020, p. 1). Lo perverso de la portada radicaría, pues, en maquillarlo todo 'de diseño y creatividad'.

Pero no es esto lo que interesa. El interés de este artículo se centra en el contenido del libro visto como una totalidad, es decir como un conjunto analítico, reflexivo y crítico con los 'tiempos de pandemia'. Y aquí empieza la discusión: estos artículos/ensayos/narrativas han sido escritos y emitidos, no cuando la pandemia ha sido controlada o resuelta por las ciencias físicas y médicas, sino cuando está en incontrolable expansión por el mundo. Hay, por tanto, una 'simultaneidad' de la filosofía con la pandemia. La polémica, según Zarria (2020), surge porque hay quienes piensan que esta 'simultaneidad' es impropia de la filosofía, que a esta 'le viene mal la prisa's, y que esta premura de la filosofía 'no conduce a la montaña, sino al barranco'.

\section{Más leña al fuego}

La publicación de múltiples artículos/ensayos por parte de filósofos mundialmente reconocidos en los mismos días en los que la pandemia 
ataca sin misericordia, pone sobre el tapete algo que merece ser pensado: que la filosofía, en este tiempo, no es ni la lechuza de Minerva ni la Mensajera del Alba. Esos filósofos están diciendo, en realidad, que la filosofía en tanto 'su tiempo aprehendido en pensamientos' poco o nada tiene que ver ni con el 'crepúsculo' (para lo cual se requeriría ahora 'callar y pensar,' 'detener la pluma,' 'abrir la ventana'), ni con el 'alba' (que supondría profecía, predicción, vaticinio, con el correspondiente apresuramiento). Ni siquiera cabe la posición intermedia de González y Martínez (2020), dispuesta a "hacer el esfuerzo de arrojar pensamientos inconclusos y balbuceantes, pues la filosofía tiene la responsabilidad de aportar sentidos y conceptos, de nombrar las cosas, de indicar caminos" (p. 1).

La filosofía para ser tal debe concebir (poner en conceptos) 'lo que es'. 'Lo que es' es la razón, según el idealista Hegel, pero no para Marx (1973) — por ejemplo — para quien 'lo que es' es la realidad material. Y es esta realidad material (el Covid-19 como virus de la muerte y las circunstancias materiales de su aparición) la que determina/condiciona al pensamiento. Por cierto, que la filosofía ha sido, es y será un asunto de la razón que piensa, abstrae y conceptualiza, pero no de la razón que se piensa a sí misma (Hegel), sino de la razón como capacidad de pensamiento determinada/condicionada por la realidad material. Cuando la filosofía se atiene a estas determinaciones, no puede ir más allá de su tiempo porque "es solamente la conciencia de lo sustancial de su tiempo, o el saber pensante de lo que existe en el tiempo" (Hegel, 1980, p. 108).

Pues bien, si la filosofía sólo puede pensar el tiempo presente y el presente del mundo es la pandemia de coronavirus que nos acosa y sobrecoge, pretender que deba emprender su vuelo al caer la noche (futuro incierto) es pretender 'ir más allá de su tiempo presente', lo cual es 'insensato' (es decir, no ajustado a las determinaciones de la razón que piensa el tiempo presente). Estas determinaciones de la filosofía afectan también al filósofo como individuo y lo ha advertido Hegel (1980):

(...) ningún individuo puede saltar por encima de su tiempo [...]; el individuo es hijo de su época; lo esencial de la época es su propia esencia [...]. Nadie puede salir de lo esencial de su época, como nadie puede salir de su propia piel (p. 108).

Por consiguiente, ni la filosofía ni el filósofo pueden, en una consideración esencial, saltar su tiempo presente y ubicarse cómodamente en el 'atardecer' (refugio de los idealistas, donde lo ideal prima sobre lo real). 


\section{Solo bajo un aspecto, la filosofía puede estar por sobre su tiempo}

Solo bajo un aspecto, la filosofía puede estar por sobre su tiempo, dice Hegel: en tanto Razón que se identifica en último término con el espíritu mismo en el más elevado florecimiento de sí mismo. Solo en este aspecto formal (que, por cierto, para Hegel es lo real), la filosofía 'está por encima, porque es el espíritu que se conoce como contenido', porque 'es verdaderamente la realidad del espíritu' (Hegel, 1975).

Se manifiesta así "lo ideal frente a lo real y se hace cargo de este mundo en su sustancia” (p. 63). Este mundo real, lleno de desorden y desdicha, de engaño y corrupción, ya no satisface, se rompe, declina, cae; entonces aparece la filosofía como reconciliación de esta decadencia, pero "esta reconciliación ocurre en el mundo ideal —insiste Hegel— en el mundo del espíritu, en que el hombre se refugia, cuando el mundo terreno ya no le satisface" (Hegel, 1980, p. 111). Esta filosofía como reconciliación simboliza Hegel (1980) con el Búho de Minerva que emprende su vuelo al romper la noche:

Si la filosofía se presenta y - pintando gris sobre gris- despliega sus abstracciones, entonces ya pasó el fresco color de la juventud, de la vida. Luego es una reconciliación lo que ella produce, pero solamente en el mundo del pensamiento, no en el terrestre (p.111).

Es lógico que la filosofía-como-Búho-de-Minerva piense lo que ya pasó, lo ya acaecido, lo que no se puede 'rejuvenecer' sino solo 'conocer'.

Quienes defienden esta visión vesperal de la filosofía afirman en realidad que en el contexto actual aún no es tiempo para la filosofía, que el mundo en el que vivimos todavía no ha entrado en decadencia, que hay que esperar, ser cautelosos, pacientes, prudentes, serenos, humildes y dejar que las ciencias empíricas hagan y digan lo que les corresponde, tal como expresa Zarria (2020). Mientras tanto la filosofía debe callar, aunque sea por un tiempo, detener la pluma, abrir la ventana, esperar pacientemente al atardecer, cuando las ciencias físicas hayan dicho todo sobre la pandemia. Y entonces filosofar.

\section{Más allá de Hegel}

Hay quienes piensan que el espíritu de la época que vivimos —esta Modernidad capitalista, colonial, patriarcal, individualista - viene dando desde décadas atrás muestras de decadencia y que es ahora el tiempo de la filosofía, no después. Múltiples manifestaciones ponen de relieve esta 
decadencia: el conocimiento como poder de dominación/marginación; el predominio absoluto del Yo; la razón instrumental; el capitalismo, el neoliberalismo y el individualismo salvajes; la explotación irracional de la naturaleza, el calentamiento global y el deshielo de los polos; la migración de millones de personas que huyen de la pobreza y el abandono; la concentración de la riqueza en pocas manos; la primacía del mercado sobre los seres humanos y la explotación criminal de los obreros; la pérdida de valor del trabajo, de la solidaridad, de lo comunitario; el racismo; la xenofobia; las pandemias del siglo XXI y, sobre todo, la pandemia de Covid-19 que ahora mismo sumerge al individuo y a la sociedad en general en el pavor y la muerte, en el confinamiento y la soledad.

¿Qué esperan los que defienden la tesis de la filosofía como mochuelo de Minerva? cuando sostienen que es necesaria una reflexión pausada, que hay que esperar que la pandemia se haya consumado para que la filosofía pueda pensar sobre lo ya acaecido, que a la filosofía "le es imperioso el carácter de lentitud, de rumiar conceptos y argumentos, de una lectura atenta, detallada y parsimoniosa de la realidad" (Sicerone, 2020). Pausa, lentitud, parsimonia, mesura, prudencia, paciencia; callar, rumiar, esperar: este es el lenguaje de quienes aún esperan el crepúsculo para pensar. Mientras tanto, lo esencial de nuestro tiempo que es la vida amenazada por los desarrollos/patologías de la misma modernidad y de la pandemia actual, se les escapa como agua entre los dedos. Mientras tanto, la gente sufre, muere y no es feliz - como diría Camus-.

Si estamos en una de las decadencias que develó Hegel para las distintas etapas de la historia humana, esto significa que hoy es el tiempo de la filosofía, pues hoy (y no cuando la pandemia haya caducado) el pensamiento es vida, actividad, necesidad, determinación. Por supuesto que la filosofía debe estar atenta a lo que digan las ciencias físicas, médicas y sociales, pero ella tiene campos específicos (ontológicos, epistemológicos, antropológicos, éticos, políticos...) que reclaman ser pensados desde ya. ¿Para cuándo habría que postergar el pensar, por ejemplo, acerca de quiénes somos hoy y cuál es nuestra relación con el logos (razón, conciencia)?, ¿cuál es el sentido de vivir, de morir, de sufrir, de estar solos?, ¿cómo nos autocomprendemos los seres humanos frente a la pandemia?, ¿qué es la bondad o la maldad en el contexto de la pandemia mundial, que tiene caracteres específicos en la realidad en la que cada uno se encuentra?, ¿cuáles son las actitudes éticas correctas frente a los otros y frente a mí mismo?, ¿¿cuál es el verdadero sentido de las decisiones del Estado?, ¿¿cuáles son las implicaciones filosóficas de seleccionar los que deben morir y los que deben vivir?... Es ahora, frente a la emergencia mundial y local, 
cuando la filosofía puede re-comenzar, justificar su existencia y considerarse necesaria al espíritu pensante.

Pero Hegel es Hegel y no debemos olvidar que su idealismo le hace mirar a la filosofía como un aspecto de la configuración total del espíritu, como la reconciliación del espíritu consigo mismo, lo cual ocurre solo en el ámbito formal, el de los puros conceptos. Con esta visión, Hegel puso las cosas 'de cabeza' (el espíritu como esencia de la realidad). Por suerte, hubo en la historia de la filosofía quien volvió a poner las cosas 'de pie' y la filosofía, reubicada en el ámbito de la materialidad, de la vida amenazada, ha vuelto a ser el pensamiento que atiende una necesidad objetiva: la de no solo interpretar de diversas maneras el mundo, sino de 'transformarlo' (Marx, 1973, p. 11).

\section{Otras condiciones inherentes a la filosofía}

Para evitar ser considerados profetas, futurólogos, catastróficos o apocalípticos, los filósofos profesionales han asumido su tarea de pensar 'lo que es' (su realidad, su tiempo y la razón que los piensa), ubicándose en el horizonte temporal que los acoge y poniendo en marcha determinadas metodologías y esquemas categoriales ordenados y sistemáticos que les han permitido avanzar de la realidad a los conceptos, de los hechos a los fundamentos. Este procedimiento que les permite a los filósofos comprender las determinaciones últimas de una realidad específica o global, es coetáneo con los hechos y su valor debe ser medido por la posibilidad de problematizar y conceptualizar la realidad, la historia, los hechos y la razón misma que los piensa, en búsqueda incesante de lo sustancial de esta época, y no debe ser medido por aspectos psicológicos como la prudencia, la paciencia, la serenidad, la espera.

La filosofía puede conceptualizar y debe hacerlo muchas veces bajo las demandas presentes de una realidad que exige que el sentido de su acaecer sea ex-puesto (sacado a luz) mediante la razón pensante en un análisis global y sustentado. Se trataría entonces, si se quiere llamarla así, de una filosofía del presente (Marx, Nietzsche, Heidegger, Benjamin).

En otros casos, la filosofía llegará ciertamente a juzgar (hacer juicios) después de que han ocurrido los hechos y la realidad ha concluido su despliegue, pero esta es una posibilidad formal que se encuentra en las antípodas de la materialidad de los hechos. Y en esas antípodas del pensamiento formal, es posible — lo ha dicho el mismo Hegel— 'plasmar cualquier cosa'.

Lo sensato es que la filosofía se atenga a las condiciones de posibilidad que la misma realidad le ofrece, como pudo experimentarlo el más 
fervoroso idealista que no pudo esperar a que la realidad de su tiempo madurara y que se afanó en finalizar la redacción de la Fenomenología del Espíritu al tiempo que retumbaban los cañones napoleónicos en los alrededores de Jena. Esto demuestra que el mismo Hegel, al menos en esa ocasión, hacía filosofía mientras la realidad estaba en proceso, sin esperar el vuelo de la lechuza de Minerva. Estas contradicciones, ¿anulan el pensamiento de Hegel? No, como tampoco el pensamiento de los filósofos actuales queda anulado por el hecho de que se contradigan o cambien su visión. Lo decisivo es que el filósofo piense sistemática y rigurosamente lo sustancial de su tiempo, todo lo demás entra en el campo de las vicisitudes normales del pensar, cuando se tiene el valor de pensar.

Finalmente, se darán casos también en los que la filosofía piense el futuro que no existe pero que es necesario pre-verlo, anticiparlo, diseñarlo con la razón y el análisis: pensemos por ejemplo en Feuerbach, anticipando una filosofía del futuro ${ }^{6}$, o Nietzsche, escribiendo para dos siglos después ${ }^{7}$.

\section{¿Jaque-mate a las filosofías vesperales y matinales?}

En suma, la filosofía no depende de actitudes psicologizantes como la prisa o la paciencia, la serenidad o la humildad. Está en su poder el pensar la emergencia provocada por el Covid-19 con la profundidad, el análisis y la crítica que le son específicas. La idea de que la filosofía solo podría decir palabras definitivas sobre el Covid-19 cuando la pandemia haya pasado y el mochuelo de Minerva haya emprendido su vuelo al anochecer parece además irreal: a) porque la realidad está siempre en movimiento y nunca está 'lista y terminada', pues aquello que se considera ya 'realizado' no es sino la imagen y el dinamismo de un nuevo momento; $y, b$ ) porque el pensamiento tampoco descansa nunca y siempre surgirán aspectos, enfoques, comprensiones, conceptos, que no fueron vistos, considerados o evaluados a la hora del crepúsculo.

Si el pensar filosófico consiste en aprehender en conceptos un tiempo determinado, eso depende: a) del nivel de autoconciencia que sea posible en este tiempo en los distintos ámbitos donde se realice la reflexión, b) de los recursos/fases/métodos inherentes a la filosofía como pensamiento sistemático: vínculo con situaciones límites o extremas, racionalidad, visión de totalidad, proceso de abstracción, radicalidad, generación de conceptos, rigurosidad, criticidad, problematización, trascendentalidad, etc. ${ }^{8}$.

Los filósofos que han escrito sobre la pandemia cumplen a cabalidad los requisitos esenciales de la filosofía como tal, y son estos los que 
dan consistencia a sus ensayos, independientemente de lo debatible que puede ser lo que cada uno sostiene. Al depender de los caracteres inherentes al propio pensamiento, por un lado, y del compromiso de aprehender su tiempo en conceptos, por otro lado, sus aportes muestran la contemporaneidad que le cabe a toda filosofía como saber comprometido con las demandas esenciales de su entorno.

Esto poco o nada tiene que ver con una visión conservadora del filósofo, que lo confina a un aislamiento intelectual, además del aislamiento físico, en el cual supuestamente podría desarrollar una reflexión 'mesurada' y 'rumiada'. Los filósofos antologados en el libro La sopa de Wuhan y otros tantos filósofos y pensadores (Jürgen Habermas, Edgar Morin, Alain Touraine, Emilio Lledo, Roberto Espósito, Martha Nussbaum, Adela Cortina, Enzo Traverso, Fernando Savater, Enrique Dussel, Naomi Klein, Amelia Valcárcel...) que han hecho sus publicaciones en distintos medios, han roto el prejuicio que les conmina a 'callar' cuando la pandemia está en pleno desarrollo y a 'pensar' cuando ella haya caducado.

La 'contemporaneidad' de quienes piensan 'simultáneamente' a los hechos, si lo hacen con los parámetros y los métodos propios de la filosofía, no les convierte en comentadores matinales, ni en pronosticadores de un tiempo incierto, ni en opinólogos con un barniz de filosofía, ni en autores de un pensamiento provisional. Sus reflexiones, por breves que sean, han demostrado que no hay que esperar al crepúsculo o al alba sino disponer en todo momento de una razón pronta, una mirada atenta, un claro marco de análisis y una 'caja de herramientas' (Wittgenstein) que les permita llegar a las determinaciones últimas de la realidad que incita su reflexión. El hecho estimulante es que los filósofos han respondido prontamente, desde sus respectivos horizontes de comprensión, a la demanda de sus respectivas realidades, sin que convirtieran a la filosofía de 'mochuelo de Minerva' en 'mensajero del alba'.

Ni vesperal, ni matinal, la filosofía más bien planta sus reales donde y cuando las sociedades o los pueblos requieren disponer de ciudadanos comprometidos con la tarea de pensar y sacar a luz los conceptos que expresan el sentido de lo que acaece. Y eso le basta y sobra a la filosofía.

\section{De la "metafísica del ser universal" a las "onto-logías históricas del ser-aqui". La dialéctica ser/no-ser}

Pensado desde un horizonte latinoamericano y del Sur Global, o sea desde un contexto de colonialidad y pandemia (que es el que nos corresponde y desde dónde debemos pensar para filosofar con sentido), se ve que 
la cuestión del 'ser' se ha visto enfrentada a situaciones históricas nuevas y significados nuevos que han posibilitado una nueva forma de entender la clásica exclusión parmenídea entre 'ser' y 'no-ser', que está en la base de la metafísica eurocéntrica.

El 'no-ser', al que quedó reducido el indígena americano por la cosificación/asesinato ético del que fue objeto por la conquista y colonización, se convirtió en una variante negativa del mismo 'ser' que posibilitó la degradación de los indígenas, negros y mestizos a la condición de objetos, instrumentos, seres cuasi-humanos, bárbaros sin alma, sin razón, sin espiritualidad, que debían ser violentamente incorporados a la civilización y a la cristiandad. Esta razón metafísica explica que la historia latinoamericana de los últimos cinco siglos haya sido la de un 'ser' disminuido, depredado, despotenciado, menoscabado, deshumanizado por la mirada del conquistador y del sistema imperial impuesto: esto es, un 'no-ser'. Un 'no-ser' que, a pesar de la visión nihilizadora que propició el genocidio indígena y el arrasamiento de sus culturas, persistía en no quedar fuera del 'ser'.

El 'no-ser' americano no estuvo ni está fuera del ser, estuvo y está allí como negatividad inserta en el mismo 'ser', que puede ser superada utilizando una dialéctica ontológica de carácter histórico. Puesto que el 'no-ser' no es la nada, salir del 'no-ser' significa que los entes negados se re-conocen como existencia, como vida, como 'ser-aquí. Esta visión re-constitutiva de sí mismos (de nosotros mismos) como 'ser-aquí' que supera el 'no-ser' colonialista, es lo que denominamos 'onto-logía histórica del ser-aquí.

La consecuencia de todo esto es que la filosofía en América Latina y el Sur Global no puede acogerse sin más al 'final de la filosofía como metafísica' pregonado por un Heidegger eurocentrado, sino que tiene que re-definirse como una disciplina que piensa las condiciones de posibilidad de nuestra re-constitución como 'ser-aquí', junto a la re-habilitación del lógos (razón, racionalidad, conocimiento, discurso) latinoamericano. Esta re-constitución del 'ser-aquí' y el lógos, como imperativo del presente, lleva a redefinir la ontología como onto-logía, es decir como un logos de los entes histórico-temporales, concretos y situados, abiertos a lo otro (la naturaleza) y a los otros que conviven con nosotros en un mundo que, de 'ancho y ajeno's se busca convertirlo en casa común.

Este esquema posibilita que la metafísica eurocéntrica apareciera como lo que ha sido en nuestra región: 'ciencia' que manipuló ideológicamente la concepción parmenídea del 'ser' y el 'no-ser' en sus guerras de expansión y coloniaje. Al establecerse como un sistema de categorías 
que piensa la re-constitución y despliegue del ser-aquí- latinoamericano y su lógos, la onto-logía histórica se convierte en una posibilidad concreta de descolonización ontológica que deconstruye desde sus mismos fundamentos la metafísica eurocéntrica.

\section{El verdadero poder de la filosofía}

La filosofía demuestra su máximo poder cuando es capaz de llegar con sus métodos y su pensamiento reflexivo, riguroso y sistemático, a la sustancia, el arché, la causa última, el fundamento de lo existente. La filosofía que ex-presa o saca a luz estos determinantes últimos del mundo-realidad se convierte entonces en la razón pensante, en la conciencia de su tiempo o su tiempo aprehendido en conceptos, como lo señalaba Hegel. Esos determinantes últimos pueden ser y han sido distintos en las diferentes épocas del desarrollo del pensamiento filosófico: el espíritu absoluto (Hegel), la alienación socio-económica (Marx), el desfondamiento de los valores universales y absolutos (Nietzsche), el ser-ahí como temporalidad (Heidegger), la existencia precediendo a la esencia (Sartre)... Se puede mencionar, igualmente, en una visión retrospectiva: la Naturaleza (Spinoza), el Yo (Descartes), Dios (Escolástica), el Uno (Plotino), el Ser (Aristóteles), el Bien (Platón)... Cada uno de estos fundamentos han sido pensados como la esencia de lo que es, $y$, en consecuencia, como determinante último de la realidad.

El 'Ser' como fundamento teórico ha sido el tema tradicional de la Metafísica/Ontología desarrolladas por Europa. Al definirlo en último término como Dios (Aristóteles, cristianismo), tal metafísica se transformó en onto-teo-logía. A pesar de las distinciones de razón que Europa realizó entre 'Metafísica' y 'Ontología', las utilizó indistintamente (y ambiguamente) para aludir siempre a lo mismo: el 'Ser/Dios' como fundamento universal y absoluto. Basada en esta in-distinción, la Europa moderna-expansionista llevó esta filosofía y la impuso en todas partes como verdad única y absoluta, eterna y necesaria. Europa convirtió de esa manera la filosofía onto-teo-lógica en ideología política de expansión (pensamiento o visión del mundo utilizada como justificación o encubrimiento de las conquistas y los colonialismos) al servicio de los poderes imperiales que conquistaban y dominaban el planeta.

Bajo esta condición, la filosofía como metafísica llegó a América en el siglo XVI, se mantuvo como tal a lo largo de los diversos colonialismos de los últimos quinientos años (español, portugués, inglés, francés, holandés, norteamericano); y ha logrado 'licuarse' e instalarse en la mente 
y el alma de los colonizados como 'cultura occidental y cristiana', hasta el día de hoy. En las academias, por supuesto, el asunto corría más fácil: el estudio de la metafísica aristotélico-tomista era (y es todavía hoy en centros católicos) obligatoria.

Para estructurarse como saber sistemático en Europa, la filosofía organizó su abanico de saberes en 'disciplinas': el saber sobre el ser-dios (metafísica/ontología, teología), sobre el conocimiento y la verdad (lógica, epistemología), sobre el mundo-cosmos (cosmología), sobre el hombre (antropología), sobre los actos humanos (ética), sobre la belleza y el arte (estética)... Para 'licuarse' como cultura (volver digerible o asimilable el significado de los conceptos abstractos para la gente común) e instalarse en la mente y el alma de los colonizados, se empleó la predicación y el temor religioso, la educación escolar y colegial, y la lenta y sostenida configuración del mundo de valores y costumbres. El tronco que ha sostenido y sostiene todavía a 'esa filosofía greco-europea' impuesta como 'filosofía única y universal', ha sido y es la metafísica/ontología.

Este 'saber metafísico' que configuraba un mundo ideal en Platón, se convirtió en real politik con Aristóteles y ha acompañado desde entonces los expansionismos greco-romano-europeo-norteamericanos. Los sucesivos imperios mundiales fundamentaron teóricamente sus guerras de expansión, conquista y colonización en la distinción metafísica (y, por tanto, universal y necesaria) entre ser/no-ser, y de ella extrajeron las derivaciones conceptuales de civilización-barbarie, fe-razón, cristianosinfieles, progreso-subdesarrollo, libertad-naturaleza, pueblos históricospueblos sin historia, democracia-tiranía..., que les sirvieron y les sirven para someter y dominar.

En síntesis: el verdadero poder de la filosofía impuesta en América radicó en esta visión onto-teo-lógica utilizada como ideología política que definió y define como 'no-ser' a las realidades descubiertas y colonizadas, conminándolas a la barbarie, a la irracionalidad, a la inautenticidad, al subdesarrollo, a la a-historicidad. Más allá de la visión de totalidad y la rigurosidad lógica de sus conceptos, la metafísica del ser universal fue utilizada en la praxis de la política y de la vida cotidiana como un instrumento para discriminar, separar, ocultar, negar, invisibilizar, desvalorizar ${ }^{10}$.

\section{Necesidad de una crítica de la condición metafísica}

¿Cómo ha sido criticada o superada esta condición metafísica de la filosofía? Europa se ha purgado a sí misma mediante una paulatina decons- 
trucción de su horizonte onto-teo-lógico a lo largo de la modernidad, hasta culminar en Heidegger y Sartre, quienes realizaron las conceptualizaciones postreras acerca del 'fin de la filosofía como metafísica' y el 'fin de las filosofías de la esencia'.

¿Y Latinoamérica y el Sur Global? ¿Cómo los ámbitos donde prevalece todavía la colonialidad requerirían orientar su pensamiento para superar la metafísica eurocéntrica y colonialista del ser universal y absoluto? Si esta metafísica está licuada e instalada en los resquicios más profundos del ser, sentir, pensar, creer, ¿ ¿ómo salir de ella? ${ }^{11}$.

Salir de ella llevará tiempo y un laborioso esfuerzo por filosofar desde nuestras realidades. La categoría del 'ser' como fundamento sigue operando en los trasfondos de las culturas latinoamericanas actuales, aunque no se quiera verlo o comprenderlo. El asunto, por tanto, si queremos mantenernos en el horizonte de lo que usualmente se entiende por filosofía, es re-definir o re-semantizar la cuestión del 'ser' desde o a partir de condiciones existenciales e históricas que permitan abrir el pensamiento a la cuestión del 'ser-aquí. ¿Con qué recursos teóricos, críticos, deconstructivos, lograríamos esto? Con estos, por ejemplo:

- Descubriendo nuestra real ubicación en la historia mundial y en la geo-política de nuestro tiempo, que supere la tradicional división eurocentrada de la historia mundial en edad antigua, media y contemporánea ${ }^{12}$.

- Conquistando una "cabeza de playa en el ámbito de lo ontológico y epistémico" como espacio inicial en/para el despliegue de saberes decoloniales y de liberación.

- Introduciendo una clara y tajante distinción entre "metafísica del ser universal " y "onto-logías históricas del ser-aquí", que ponga al descubierto o saque a luz el carácter imperial de la metafísica eurocéntrica y las nuevas posibilidades teóricas de las onto-logías históricas del ser-aquí1 ${ }^{13}$.

- Apelando a nuevos 'lugares -loci-filosóficos' y elaborando teoría desde los colonizados y no desde los colonizadores, desde los negados por el sistema como no-ser, es decir como objetos, cosas, animales de trabajo, vituperables, prescindibles.

- Poniendo en crisis el logos (razón, palabra, ciencia) greco-europeo-norteamericano impuesto como horizonte universal de comprensión, y evidenciando un logos decolonial que posibilite una comprensión, lectura y expresión de nuestra existencia y realidades históricas. 
- Apropiándonos, re-semantizando o procesando nuevas categorías de pensamiento, válidas en el ámbito de la filosofía, como: 'onto-logía histórica de nosotros mismos', 'alteridad', 'historicidad', 'alienación', multiplicidad', 'diversidad', 'proximidad', 'mediación', 'liberación', 'deconstrucción', 'descolonización'.

- Definiendo y re-definiendo las características de una filosofía decolonial, transmoderna, ecológica, antiimperialista, antipatriarcal, antifetichista..., que piense América Latina y el Sur Global como verdaderos 'lugares filosóficos', y abra caminos de pensamiento que conduzcan a cosmovisiones incluyentes, integradoras, valorativas de nosotros mismos y de nuestras realidades sociales, económicas, políticas, culturales.

- Realizando procesos de deconstrucción/descolonización en el ámbito de las ciencias sociales, particularmente en la filosofía (deconstrucción onto-teo-lógica, epistemológica, antropológica, ético-política...), en la sociología (burguesías/élites/oligarquías vs clases medias-bajas, desclasados, marginales), en la política (gobernantes y gobernados), en la economía (dueños del capital y los medios de producción vs los que solo tienen su fuerza de trabajo), en la cultura (entre los que disponen del logos y los que lo toman 'prestado'14).

- Generando pautas de pensamiento y valores replicables o asimilables en otros campos del vivir, del saber, del hacer, del sentir, del creer, del ser hombres, del morir, del trascender.

- Logrando que circule lo ganado en el ámbito del pensamiento no solo en las academias sino en los espacios subalternos.

Una sistematización inicial de esta 'onto-logía histórica' que posibilite la re-constitución/re-habilitación/liberación del 'ser-aquí', es necesaria. Con ello habremos liberado a la misma ontología de su matriz metafísica eurocéntrica y la habremos re-formulado como onto-logía, como lógos de los entes históricos y de lo que tiene que ver con estos: la propia existencia, la vida, el tiempo, el mundo, la naturaleza... Se abre así la posibilidad de pensar desde otro horizonte (o desde un horizonte 'otro') problemas vinculados al ente histórico como el de la vida amenazada por la pandemia y los colonialismos, la verdad, la eticidad, el humanismo, etc., que son problemas que tiene que ver en último término con el 'ser-aquí' que somos y con el lógos que permite pensar y pensar-nos. 


\section{Las onto-logías históricas como mecanismos de descolonización filosófica}

Más allá del uso político (transformación de la sabiduría acerca del ser en ideología política de expansión y conquista) que Europa hizo de la filosofía, esta alcanzó en los siglos griegos un rango ontológico que se convirtió en una condición sine qua non para toda filosofía ${ }^{15}$. Los griegos no inventaron la filosofía, pero descubrieron la cuestión del 'ser' como su determinación fundamental. Esto sigue vigente en Occidente y obliga a la filosofía que pretende serlo en sentido riguroso, a alcanzar siempre ese rango ontológico.

Es el 'giro imperial' de la filosofía eurocéntrica que definió a lo noeuropeo como no-ser lo que los ámbitos coloniales critican y rechazan. Latinoamérica y el Sur Global requieren buscar el ángulo onto-lógicodescolonizador que permita avanzar del ser negado (depredado, despotenciado, ocultado, desvalorizado) al ser histórico que somos, al 'seraquí $^{16}$. Tampoco se trata de imitar la superación del horizonte ontológico que Europa llevó adelante; la cuestión radica en la crítica radical del 'serimperial' que posibilita el re-posicionamiento de los ámbitos colonizados en el 'ser' como 'ser-aquí'.

Independientemente de los usos y abusos que Europa haya hecho de la filosofía-como-metafísica, quienes pretendemos hacer filosofía tenemos que sentirnos llamados por la cuestión del ser que somos y, en consecuencia, por una onto-logía de nosotros mismos. La filosofía debe expresar esta determinación onto-lógica y encontrar el camino que conduzca del 'no-ser' al 'ser-aquí'.

Esta orientación del pensamiento posibilita la crítica de la filosofía eurocéntrica, postulada hasta el día de hoy en las academias, en los foros, y en la cultura alienada como única, universal y absoluta. Se requiere asumir la criticidad inherente a la misma filosofía y liberar la posibilidad de pensar nuestra propia descolonización filosófica. En la medida que se alcance un rango onto-lógico (del no-ser al ser-aquí), la filosofía será verdadera sabiduría, verdadera búsqueda de la verdad del ente.

A algunos les puede confundir que se postule una onto-logía del ser-aquí frente a una Europa que ha discutido de manera sostenida en los últimos cuatro siglos la superación del horizonte ontológico. El 'fin de la metafísica' consiste, según Heidegger ${ }^{17}$, en superar la cuestión de 'qué es ser' y pensar en adelante el 'sentido del ser'. Esto corresponde legítimamente a la realidad europea. Para nosotros, los hijos del colonialismo, el verdadero problema onto-lógico de nuestro filosofar es pensar quiénes 
somos hoy y cómo es posible nuestro ser-aquí. Es este proceso onto-lógico lo que tiene que poner en conceptos la filosofía. De este modo, la filosofía seguirá siendo filosofía, pero pensada en/desde ámbitos coloniales que luchan por su liberación.

\section{La vida como manifestación privilegiada del 'ser-aqui' en tiempos de pandemia}

\section{Las onto-logías históricas frente a la pandemia}

El desocultamiento/emergencia del 'ser-aquí' constituye el fundamento onto-lógico de un proyecto descolonizador/liberador en los ámbitos del pensamiento. Sobre esa base podremos hablar de filosofía con legitimidad pues habremos re-convertido la filosofía eurocéntrica en saber de descolonización, subjetivación y realización histórica de nosotros mismos. Este proyecto engloba a colonizados y colonizadores y abre caminos para comprender y enfrentar los múltiples problemas que el tiempo histórico nos presenta, unos más graves que otros, como la pandemia de coronavirus que nos acosa.

Todos, los que conceptualizan y los que simplemente viven el problema, han/hemos enfrentado la pandemia de Covid-19 en términos de experiencias directas, inéditas o re-significadas. Entre ellas: la experiencia de la propia existencia, no en términos abstractos sino en su presencialidad y singularidad únicas; la experiencia de la vida amenazada; del cuidado de sí; de los Otros como proximidad o amenaza; del peligro inminente de morir; de la soledad; del uso político de la fragilidad humana; del menosprecio de la vejez; de la polisemia del lenguaje y la manipulación de los significados por parte de los gobiernos o las élites dominantes; de la esperanza en la ciencia como recurso salvador; de la fe alicaída; etc. Estas y otras experiencias, convertidas en presente inescapable de los que viven, mueren, sufren, se quedan o se van, sacan a luz la temporalidad e historicidad del 'ser-aquí.

La experiencia fundamental ha sido la de la propia vida, de su valor, de su poder, de su vulnerabilidad. No menos intensa ha sido la experiencia de la muerte, de la enfermedad, del sufrimiento físico, de las despedidas sin presencia ni consuelo de los seres amados. La experiencia del confinamiento y la soledad ha marcado también la vida de muchos. El mundo de posibilidades frente a las cuales se puede elegir se ha reducido. El poder político, el poder militar, el poder económico han dejado ver 
su sobredimensionamiento e ineficacia al momento de proteger o salvar la vida de los conciudadanos. La sociedad del espectáculo se ha sentido y se siente desguarnecida. Las desigualdades sociales se han relativizado - para quienes creen en el poder igualador de la muerte- o se han remarcado - para quienes se alejaron de la contaminación basados en su poder económico- L La normalidad en la que vivíamos se nos apareció de pronto como insuficiencia, como crisis, como riesgo biológico. La 'nueva' normalidad, según la perspectiva del que la mira, la juzga o la sufre, es una incógnita o un desafío.

Además de estas, Latinoamérica y el Sur Global han tenido otras experiencias históricas que interesan a la filosofía. En primer lugar, la experiencia de la universalidad. Esta ha permitido que, más allá de la colonialidad o a pesar de esta, dichas regiones se identificaran, no como el 'patio trasero' de ninguna potencia, sino como parte integrante de un todo universal interpelado por la pandemia. Ha quedado claro que una cosa es el concepto de lo universal generado por la metafísica, y otra - muy distinta - es la experiencia de lo universal como constituyéndonos desde dentro. Nosotros, los colonizados, que a causa del colonialismo habíamos sido relegados al ámbito de la particularidad, la subvaloración y el olvido, emergimos con la pandemia como parte integrante de una totalidad que nos incluía a pesar de las diferencias regionales, políticas, raciales, culturales o tecnológicas. Los ámbitos coloniales tuvieron, en pleno siglo XXI, la experiencia de lo universal que Europa tuvo, por ejemplo, a partir del siglo XVI con el sistema-mundo generado por el expansionismo y el colonialismo.

Junto a estas experiencias históricas, Latinoamérica y el Sur Global han tenido también la experiencia intelectual-filosófica de lo onto-lógico, del 'ser-aquí', de la existencia, del mundo, de la vida, y de la muerte como manifestaciones universales de lo que es, aquí y ahora, en la historia, aunque puede dejar de ser por el coronavirus.

\section{Respuesta a los desafíos generados por la pandemia en el plano del pensamiento}

Estas experiencias de lo fundamental y sustancial, de lo histórico y circunstancial (circum-stare) y esta necesidad de pensar nuestra realidad y de pensar-nos para llegar a los determinantes últimos de nuestra existencia, se han visto reflejadas en artículos y estudios publicados en los últimos meses, que manifiestan una pre-ocupación y un afán inusitado de comprender, no solo las causas de la pandemia, sino la 'singularidad universal' (Kant) de la existencia y la vida humana. 
Hay que fijarse sobre todo en la vida, la vida humana interpelada por un microscópico virus. Aquí, la filosofía se ha esforzado por entender el problema desde las realidades que nos conciernen. Como una muestra de ello, se puede mencionar a dos filósofas mexicanas que, sin renunciar a pensar desde los determinantes de su región, alcanzan un universalismo crítico que evita premeditadamente naufragar en una 'repetición compulsiva' de lo dicho por 'reflexiones europeas, norteamericanas y masculinas' ${ }^{18}$.

De acuerdo con González y Martínez (2020), hay aquí una actitud filosófica que debe caracterizar las reflexiones latinoamericanas y del Sur Global:

No es lo mismo [sostienen] pensar en tiempos de este coronavirus desde los países europeos con sus sistemas de salud, que se han visto rebasados y sus economías que anticipan una crisis, que, desde los países latinoamericanos, con sistemas de salud que ya estaban de por sí saturados y desabastecidos, con economías para las que esta crisis será sumada a las otras. [Y añaden:] Es corto de miras y eurocéntrico juzgar que el encierro que se vive en España, Italia o Francia es solo por coerción del Estado, sin siquiera hacer el ejercicio de imaginación de que, en otras latitudes, por ejemplo, en México, esto ha sido el privilegio de unos cuantos. [Se reafirman en que] las interpretaciones que la filosofía tiene que hacer han de ser más plurales, más sensatas y más respetuosas de las diferencias (p. 1).

\section{La vida como fundamento y categoría}

Las filósofas mexicanas María Antonia González Valerio y Rosaura Martínez Ruiz (2020) encaran el tema de la vida como categoría, afirmando que es para ellas:

(...) particularmente relevante el entendimiento de la categoría de vida al margen u opuesta a la de cultura. Sobre todo, porque corresponde a un cierto paradigma e ideario biológico del siglo XX que se ha afanado por separar lo vivo, para estudiarlo y determinarlo en términos mecanicistas. [... y enfatizan] ¿cómo hablar de vida biológica, de vida neutra cuando la vida humana se da siempre en condiciones sociales, culturales, económicas, políticas y familiares de diferencia? ¿Cuándo aparece la vida humana así tal cual? Ni la vida humana ni el patógeno que ahora la amenaza se da indiferenciadamente. Es ontológicamente insostenible pretender que esta pandemia nos pone en la coyuntura de decidir entre la vida biológica y la social (p. 2). 
La vida es en sí misma un hecho biológico, social, político y cultural, por tanto, aspirar a una autonomía ontológica de la dimensión biológica resulta insostenible epistémicamente; ello debido a que "marcar cortes claros entre la materia y la idea resulta imposible o perversamente fantasioso" (González \& Martínez, 2020, p. 3). Basta abrir los ojos para ver que la actual crisis sanitaria, ética y económica ha puesto en evidencia que 'la vida nunca es desnuda' es decir, que no se da nunca fuera de la esfera pública o al margen de lo político. Y añaden las autoras con plena convicción que:

Muchos creen que lo que estamos viviendo es exclusivo de un periodo de anormalidad, cuando más bien estamos en un momento crítico de nuestra interdependencia biológica, política, ética y ontológica. En dichos términos, esta crisis no es más que un dispositivo que hace visible de manera dramática cómo nuestra vida depende y está sostenida por otras y por todos los otros seres vivos y formas de la naturaleza no viva (como el agua, el aire y las piedras) (p. 3).

Vinculado a la vida, está la cuestión del cambio climático. El mundo sabe, aunque los imperios lo ignoren, que la depredación de la naturaleza genera desequilibrios en el clima y en los efectos del clima sobre los seres vivos. La naturaleza, que para Spinoza era divina (Deus sive Natura), ha sido desacralizada y manipulada por la modernidad ilustrada. El hombre moderno (con excepción de algunas culturas indígenas) no entiende los modos de ser de la naturaleza, no convive con ella y la explota, la depreda. Ante esto, dicen las filósofas mexicanas: "el cambio climático que estamos viviendo, cuyas consecuencias serán cada vez más dramáticas y violentas, es también consecuencia de una valoración inequitativa de los diferentes modos de ser de la naturaleza" (González \& Martínez, 2020, p. 3).

La defensa de la vida involucra, no solo conceptos racionales, sino también valores, actitudes y sentimientos. Las filósofas mencionadas expresan dos sentimientos encontrados: uno optimista: "Hay un gran deseo de esperanza y confianza en la ciencia, la tecnología y la medicina" (González \& Martínez, 2020, p. 4); y uno pesimista:

Esta pandemia, con todo lo que destruya y todo lo que revele y exponga, no será ninguna coyuntura para construir otro mundo posible ni para acabar con el patriarcado ni con el capitalismo ni con el neoliberalismo (González \& Martínez, 2020, p. 4).

Las experiencias de siglos de coloniaje, de miles de crisis vividas, dejan poco lugar a la confianza en una futura existencia digna, de modo que: 
(...) las preguntas acerca del sentido y la bondad de la existencia que se lleguen a hacer quedarán diluidas apenas pase la urgencia. ¡ Qué pobreza de espíritu si pensamos que esto nos hará ser mejores! Aunque esto no niega que la crisis aclare una agenda política de luchas y resistencias para las que tendremos que redoblar esfuerzos" (González \& Martínez, 2020, p. 4).

En este horizonte, es imposible escapar de la autocrítica: de acuerdo con las autoras resulta desalentador pensar que el momento que decidimos cambiar algo solamente llega cuando "tenemos el miedo subido hasta el cuello y cuando nuestra incapacidad para asumir la muerte nos hace evadir(nos) corriendo frenéticamente en busca de soluciones" (González \& Martínez, 2020, p. 4). De todos modos, la razón tiene caminos de los cuales tampoco podemos ni debemos escapar, pues:

(...) conforme avance la pandemia e incluso cuando esta, por curso propio, alcance su fin, aparecerán nuevos e incalculables horizontes del pensar y de la acción colectiva. Por el momento, el más grande es el de construir y actuar desde una solidaridad global, aun cuando se sabe que los países con más recursos económicos están acaparando los insumos, los ventiladores, las medicinas; aun cuando quedarse en casa es un privilegio de clases sociales a lo largo y ancho del mundo (González \& Martínez, 2020, p. 5).

Finalmente, dos apuntes epistemológicos de las autoras citadas. El uno: "La crítica debe ser una intervención en el curso de la historia que la fracture para que, en esa grieta, se abra el horizonte de un futuro mejor, de un por-venir" (González \& Martínez, 2020, p. 5). Y el otro:

Debemos asociar el esfuerzo de desmantelar formas de conocimientos, marcos epistemológicos, ligados con la reproducción de prácticas objetables de poder con proyectos de transformación social que buscan lograr metas democráticas sustanciales como la libertad, la igualdad y la justicia (González \& Martínez, 2020, pp. 4-5).

Estas citas que permiten escuchar otras voces, revelan una cosa: la pandemia ha puesto sobre el tapete, una vez más, la necesidad de filosofar en el horizonte de un proyecto común de descolonización en/para los ámbitos que viven todavía situaciones de dependencia y colonialidad, como Latinoamérica y el Sur Global. Tal proyecto tiene que darse, no solo en el campo de lo socio-político-económico, sino también en el ejercicio sostenido del pensar crítico e irreverente. No se trata de una preparación previa del pensamiento para una acción transformadora posterior: el pen- 
samiento mismo ejercido y expuesto con criterios y métodos críticos es ya una forma de transformación, al menos en el plano de lo teórico. No se ve otra manera de entender la filosofía más que como un método de análisis para el conocimiento, la comprensión y la transformación del mundo. Estos conceptos no son nuevos; llevarlos a la práctica, eso es lo nuevo.

\section{Conclusiones}

Se ha revisado temas polémicos que relacionan directamente a la filosofía con la pandemia de coronavirus, entre ellos: el ocaso de las filosofías vesperales, el fin de las 'metafísicas del ser universal y abstracto', la afirmación de las 'onto-logías históricas del ser-aquí', y la emergencia de un pensar crítico-decolonial que anuncia, como legítimo ejercicio de utopía, el advenimiento de una nueva edad del mundo.

Todo esto parece significar, ahora más que en el siglo pasado, un verdadero fin de la modernidad eurocéntrica. Sin embargo, y abriendo las puertas a la polémica: la modernidad eurocentrada no concluyó cuando los postmodernos decretaron en la segunda mitad del siglo XX el fin del hombre, el fin de la razón, el fin de la historia, el fin de los grandes relatos, el fin de las ideologías, el fin de las utopías, etc. ${ }^{19}$. Tampoco terminó con la caída de los socialismos de Europa del Este (1989) que impulsó la llamada globalización. Estos acontecimientos no fueron el fin de una época y el inicio de otra, aunque así se lo haya afirmado, pues el despliegue postmoderno fue un suceso propiamente europeo, y la globalización involucró particularmente a las potencias del capitalismo avanzado. Ninguno de los dos eventos históricos tuvo alcance verdaderamente universal.

La pandemia de Covid-19, que empezó en una potencia emergente como China y que se expandió luego a nivel mundial, ha involucrado a todo el planeta. Su referente fundamental no fue la modernidad sometida a crítica o el capital financiero dividiendo al mundo en países desarrollados y subdesarrollados, sino la simple existencia y la lucha por la vida frente a un enemigo invisible y mortal. La modernidad eurocentrada y la globalización encontraron un límite insospechado en la naturaleza biológica de la pandemia, que no ha distinguido entre hegemonías, ideologías, capital o mercado.

Europa, por supuesto, seguirá siendo un referente dado su nivel de desarrollo económico, científico y cultural, pero no es más el 'centro' del mundo. Tampoco lo es EEUU a pesar de su desarrollo tecnológico y militar, pues otras potencias emergentes como China y Rusia desafían con éxito su hegemonía. El mundo ya no se concentra en determinados 
continentes, regiones o países que consideraban sus afanes expansionistas y colonialistas como una forma de universalización de su particularidad. Ante esta realidad impuesta por la pandemia, la categoría metafísica de lo universal ha perdido su valor absoluto $y$, al no ajustarse adecuadamente a las realidades existentes, ha cedido su campo teórico a otra categoría verdaderamente planetaria: lo pluriversal.

La planetarización de lo pluriversal va poniendo un verdadero fin a la modernidad que ha determinado y determina todavía la historia dependiente y colonial de los últimos cinco siglos. En la conciencia de la gente expuesta a la posibilidad de morir, los paradigmas del capital que se valoriza a sí mismo y del mercado, de la libertad y la democracia parecen ceder terreno en pro de los paradigmas del cuidado de la existencia humana y de la vida amenazada, de una relación armónica con la naturaleza, y de una apertura a múltiples formas de desarrollo y cultura. La ciencia y la tecnología puestas al servicio de los imperios deben volver la mirada al cuidado en la salud, alimentación, vivienda, educación y demás derechos postergados en grandes sectores de la población.

Estos fenómenos, generados o impulsados por la pandemia, no deben pasar desapercibidos para la filosofía. Como nunca antes, una razón latinoamericana y del Sur Global siente la necesidad de re-pensar y criticar las alienaciones heredades de la modernidad y la globalización con el fin de superarlas. Una verdadera descolonización epistemológica está en marcha. Los recursos o mecanismos señalados en la segunda parte de este trabajo pueden ayudar a este proceso.

La pandemia de coronavirus nos obliga a aterrizar en nuestras realidades y en nuestros respectivos contextos históricos. La filosofía, como no puede ser de otra manera - la otra manera sería la alienación permanente- se ha visto bajo este requerimiento y esta urgencia, como lo revelan los aportes de muchos pensadores y filósofos que en estos mismos días y coetáneamente a la pandemia han ofrecido sus reflexiones y puntos de vista. El poder de la filosofía como expresión crítica y analítica del sentido de lo que acaece está en nuestras manos. No lo desperdiciemos en devaneos teóricos descontextualizados, pesimistas o insubstanciales.

\section{Notas}

1 La llamada postmodernidad, como muchos —entre ellos, Habermas (1985)— lo han señalado, no es sino la última etapa de la modernidad.

2 Santiago Zarria (2020). El autor critica duramente a los filósofos etiquetando sus reflexiones como "opinología con cierto barniz filosófico". 
3 Sobre la portada "Sopa de Wuhan": Comunicado para ASPO (editorial) y Pablo Amadeo (editor), 1 de abril de 2020. Firman: Red de Diáspora China en España; Catàrsia, colectivo de asiático descendientes (Barcelona); Liwai, acción intercultural (Madrid); Oryza, colectivo asiático antirracista (Madrid); Tusanaje (Valencia); Compañía Cangrejo Pro. (Madrid); t.i.c.t.a.c. - taller de intervenciones críticas transfeministas antirracistas combativas (Barcelona).

4 2020, Libro editado en internet por ASPO/Aislamiento Social Preventivo y Obligatorio/, bajo la labor editorial de Pablo Amadeo, marzo de 2020.

5 María Antonia González Valerio y Rosaura Martínez Ruiz (2020). Carlos Vargas (2020) coincide con el enfoque de estas dos profesoras.

6 Véase Feuerbach (1984).

7 Véase Nietzsche $(1956 ; 2004)$.

8 Véase Guerra Bravo (2019a).

9 La expresión alude a El mundo es ancho y ajeno, la célebre novela del peruano Ciro Alegría (1941).

10 Esta visión política no pretende negar ciertos 'beneficios' que los estudiantes de las colonias extraían de la metafísica, por ejemplo: la capacidad de pensar con orden, de usar con rigurosidad los conceptos, de debatir con argumentos, de jerarquizar, distinguir, subdistinguir, etc.

11 Ni siquiera las culturas indígenas que originalmente tenían distintas visiones del mundo han podido escapar de la violenta contaminación de lo occidental y cristiano. De hecho, todas las culturas (indígenas, negras, mestizas) están inficionadas (contaminadas) de saberes y creencias impuestas por los procesos de conquista y colonización.

12 Dussel ha criticado la versión europea de la historia mundial, que aún se la encuentra en todos los manuales de estudio. El autor argentino realiza otra lectura de los procesos históricos mundiales: Cf. (2007a; 2007b;1994).

13 Nunca fue clara en Europa la separación entre "ser" y "ente": estos conceptos se utilizaron indistintamente para el tratamiento de las cuestiones que tenían que ver con 'lo que es'. Tampoco fue clara la separación entre "metafísica” y "ontología”. La Metafísica se definía como la 'ciencia del ser en general' o 'ciencia de lo ente'. Incluso cuando entró en circulación el término 'Ontología' con Christian Wolf (1679-1754), las dos 'ciencias' siguieron entendiéndose como equivalentes. Heidegger (1978) introdujo en el siglo XX la llamada 'diferencia ontológica' para distinguir entre 'ser' y 'ente', distinción que posibilitó la comprensión del hombre como 'ser-ahí', como manifestación privilegiada del 'ser'. La historia de la filosofía apareció entonces como historia de la Metafísica que llegó a su culminación (final) cuando las ciencias experimentales se separaron e independizaron de su matriz filosófica (siglos XIX/ XX). Después del "final de la filosofía como metafísica" (p. 134), Heidegger postuló un 'otro comienzo' que llamó 'Pensar': una actividad de la razón que no es ni metafísica ni ciencia y que piensa la 'esencia o el sentido del ser'. El 'ser' había sido 'olvidado' a raíz de que Platón y la filosofía posterior se ocuparan del 'ente' y no del 'ser en cuanto ser'. La ontología fenomenológica de Heidegger abordó nuevamente la 'pregunta por el ser' y abrió su camino hacia la cuestión del "ser" mediante una analítica del 'ser-ahí' o de la existencia, y de sus acontecimientos (manifestaciones históricas, eventos del 'ser'). Cf. Guerra (2019b).

14 Véase Guerra (2019a).

15 Véase Gadamer (1992). 
16 De allí que, limitarnos a repetir la ontología europea en los cursos académicos de las universidades es un modo de consolidar la colonialidad desde nosotros mismos.

17 Véase Heidegger (2002), Aportes a la filosofía. Acerca del Evento, Buenos Aires: Editorial Biblos.

18 Se trata de María Antonia González Valerio y Rosaura Martínez Ruiz, a quienes hemos criticado en la primera parte por su apego a la idea de la filosofía como Búho de Minerva, y de quienes valoramos la superación de este apego cuando hacen señalamientos críticos con respecto a la procedencia europea de los artículos relacionados con la pandemia y postulan, a la vez, la necesidad de que la reflexión filosófica aterrice en nuestra región. Véase González y Martínez (2020).

19 Habermas ya había advertido en su momento que la postmodernidad no era sino la última etapa de la modernidad.

\section{Bibliografía}

AGAMBEN, Giorgio

2020 ¿En qué punto estamos? La epidemia como política. Quodlibet, 9 de julio de 2020.

ALEGRÍA, Ciro

1941 El mundo es ancho y ajeno. Santiago de Chile: Editorial Ercilla.

DUSSEL, Enrique

1994 1492: El encubrimiento del otro. Hacia el origen del "mito de la modernidad". La Paz: Plural Editores.

2007a Política de la liberación. Historia mundial y crítica. Madrid: Editorial Trotta.

2007b Materiales para una política de la liberación. México: Plaza y Valdés Editores.

FEUERBACH, Ludwig

1984 Principios de una filosofía del futuro. Barcelona: Ediciones Orbis.

GADAMER, Hans George

1992 Hacia la prehistoria de la metafísica. Córdova (Argentina): Alción Editora. GONZÁLEZ AROCHA, Jorge

2020 Dossier: Filosofía y coronavirus. Los poderes del Gobierno y la libertad individual. Dialektika. Recuperadoe: https://bit.ly/34QoYu9

GONZÁLEZ VALERIO, María Antonia \& MARTÍNEZ RUIZ, Rosaura

2020 Covid-19: crítica en tiempos enfermos. FilosofíaぬCo. Recuperado de: https://bit.ly/3aNTUPi

GUERRA BRAVO, Samuel

2019a Repensando la filosofía, Visión decolonial y transmoderna desde Latinoamérica y el Sur Global. Quito: Abya-Yala.

2019b La ontología histórica como horizonte para la educación. Sophia, Colección de Filosofía de la Educación, 27, 51-76. Universidad Politécnica Salesiana del Ecuador,

HABERMAS, Jurgen

1985 El discurso filosófico de la modernidad. Madrid: Editorial Taurus.

HEGEL, Georg Wilhelm Friedrich

1975 Principios de la filosofía del derecho. Buenos Aires: Editorial Sudamericana.

1980 Introducción a la historia de la filosofía. Buenos Aires: Aguilar Ediciones. 
Philosophy and pandemic

HEIDEGGER, Martín

2002 Aportes a la filosofía. Acerca del Evento, Buenos Aires: Editorial Biblos.

MARX, Carlos

1973 Tesis sobre Feuerbach. En Marx-Engels, Obras escogidas. Buenos Aires: Editorial Ciencias del hombre.

NIETZSCHE, Friedrich

1956 Así hablaba Zaratustra. México: Editorial Filosófica.

2004 Fragmentos póstumos. Madrid: Abada Editores.

RED DE DIÁSPORA CHINA EN ESPAÑA Y OTROS

2020 Sobre la portada 'Sopa de Wuhan': Comunicado para ASPO (editorial) y Pablo Amadeo (editor): 1 de abril de 2020.

SICERONE, Daniel

2020 La filosofía como el búho de minerva: Covid-19 o el agotamiento de la teoría crítica de la sociedad capitalista. Reflexiones marginales, 8(5), 1-15. Universidad Nacional Autónoma de México. Facultad de Filosofía y Letras. Recuperado de: https://bit.ly/37TlxV7

VARGAS, Carlos

2020 Meditaciones sobre la situación pandémica. Recuperado de: https://bit. ly/3aOeNK5

VARIOS

2020 Sopa de Wuhan. Libro editado en internet por ASPO (Aislamiento Social Preventivo y Obligatorio), bajo la labor editorial de Pablo Amadeo: marzo de 2020.

ZARRIA, Santiago

2020 Mensajeros del alba. La Jornada, Baja California. Recuperado de: https://bit. ly/2WTtyU2

ZIZEK, Slavoj

2020 Pandemia. La covid-19 sacude el mundo. E-book 978-1-68219-246-7.

Fecha de recepción de documento: 15 de julio de 2020

Fecha de revisión de documento: 15 de septiembre de 2020

Fecha de aprobación de documento: 15 de octubre de 2020

Fecha de publicación de documento: 15 de enero de 2021 